\title{
The relationship between perceived social support and severity of body dysmorphic disorder symptoms: the role of gender
}

\section{O efeito do gênero sobre a relação entre suporte social apreendido e gravidade dos sintomas do transtorno dismórfico corporal}

\author{
Luana Marques, ${ }^{1,2}$ Hilary M. Weingarden, ${ }^{3,4}$ Nicole J. LeBlanc, ${ }^{3,4}$ Jedidiah Siev, $^{1,2}$ Sabine Wilhelm ${ }^{1,3}$ \\ 1 Department of Psychiatry, Massachusetts General Hospital, Boston, MA, USA \\ ${ }^{2}$ Harvard Medical School, Boston, MA, USA \\ ${ }^{3}$ Obsessive-Compulsive and Related Disorders Clinic, Massachusetts General Hospital, Boston, MA, USA \\ ${ }^{4}$ Tufts University, Boston, MA, USA
}

\begin{abstract}
Objective: Whether social support is associated with severity of body dysmorphic symptoms is unknown. To address this gap in the literature, the present study aims to examine the association between three domains of perceived social support (i.e., family, friends, and significant others) and severity of body dysmorphic disorder symptoms. Method: Participants $(\mathrm{N}=400)$ with symptoms consistent with diagnosis of body dysmorphic disorder completed measures of symptomatology and social support via the internet. Results: More perceived social support from friends and significant others was associated with less severe body dysmorphic disorder symptoms for males, and more perceived social support from family and friends was associated with less severe body dysmorphic disorder symptoms among females. Additionally, gender moderated the association between perceived social support from significant others and symptom severity, such that perceived social support from a significant other was significantly negatively associated with body dysmorphic symptom severity in males, but not females. Conclusion: The present study implicates social support as an important area of future body dysmorphic disorder research.
\end{abstract}

Descriptors: Body dysmorphic disorders; Signs and symptoms; Gender; Social support

\begin{abstract}
Resumo
Objetivo: Não há informação sobre o impacto do suporte social apreendido sobre a gravidade dos sintomas do transtorno dismórfico corporal. A fim de investigar essa relação, este estudo visa avaliar a associação entre três dominios do suporte social apreendido (familiares, amigos, e relacionamentos amorosos significativos) e a gravidade dos sintomas do transtorno dismórfico corporal. Método: Os participantes $(N=400)$ com sintomas compativeis com o diagnóstico de transtorno dismórfico corporal preencheram questionários sobre seus sintomas e suporte social via internet. Resultados: Foi encontrada correlação inversa estatisticamente significativa entre a apreensão do suporte social por parte de amigos e relacionamentos amorosos e a gravidade dos sintomas de transtorno dismórfico corporal em homens. Do mesmo modo, foi encontrada correlação inversa e estatisticamente significativa entre a apreensão do suporte social por parte de familiares e amigos e gravidade dos sintomas de transtorno dismórfico corporal em mulheres. Além disso, gênero foi um moderador da associação entre apreensão do suporte social por parte de relacionamentos amorosos e gravidade dos sintomas de transtorno dismórfico corporal. A apreensão de suporte social por parte de relacionamentos amorosos mostrou-se inversamente associada à gravidade dos sintomas de transtorno dismórfico corporal em homens, mas não em mulheres. Conclusão: Este estudo demonstra a importância da avaliação do suporte social apreendido em estudos futuros envolvendo pacientes com transtorno dismórfico corporal.
\end{abstract}

Descritores: Transtornos dismórficos corporais; Sinais e sintomas; Gênero; Suporte social

\section{Introduction}

Body dysmorphic disorder (BDD) is characterized by an excessive and impairing concern with an imagined physical defect. Either the perceived appearance flaw is nonexistent, or the concern is distinctly excessive. ${ }^{1}$ In response to anxiety associated with the appearance preoccupation, individuals with BDD typically engage in time-consuming compulsive behaviors performed to disguise the perceived defect, such as skin picking and camouflaging body parts with clothing, makeup, hats or wigs, as well as undergoing

\author{
Correspondence \\ Luana Marques \\ Department of Psychiatry, Massachusetts General Hospital \\ One Bowdoin Square \\ Boston, MA 02114, USA \\ Telephone: (617) 726-0776 Fax: (617) 643-3080 \\ E-mail: Imarques@partners.org
}

Submitted: May 5, 2010 
permanent measures such as plastic surgery. ${ }^{2,3} \mathrm{BDD}$ usually onsets in adolescence and typically follows a chronic course. ${ }^{4}$ Studies documented community and population prevalence rates between $0.7-2.4 \% \%^{2,5,6}$ and prevalence rates in psychiatric in-patient facilities between $13-16 \%, 7,8$ making BDD a relatively common disorder. Some studies found that BDD is equally common across the genders, ${ }^{1}$ whereas other studies documented that it occurs slightly more often in women than men. ${ }^{1,2,9,10}$

$\mathrm{BDD}$ is a severe disorder associated with especially high functional impairment. Quality of life is poorer in individuals with BDD than in those with depression or medical illnesses. ${ }^{11}$ Moreover, individuals with BDD spend an average of three to eight hours daily worrying about appearance concerns, and 27$39 \%$ are considered to have delusional preoccupations. ${ }^{4} \mathrm{BDD}$ sufferers have higher rates of unemployment and lower incomes than the population at large. ${ }^{2}$

BDD is also associated with high levels of social impairment. BDD sufferers are frequently socially avoidant, live alone, or are housebound. ${ }^{2,12,13}$ Suicide rates in BDD are amongst the highest of any psychiatric disorder: $80 \%$ of BDD sufferers report lifetime suicidal ideation, and suicide attempts were documented in 24$28 \%$ of adults with BDD and $44.4 \%$ of adolescents with BDD. ${ }^{3,9}$

Considering both the high functional and psychosocial impairment in $\mathrm{BDD}$ and the accompanying heightened suicide risk, it is important to study variables associated with BDD severity. Social support is one variable that has been linked to severity of several disorders sharing similar features with BDD, such as obsessive-compulsive disorder (OCD; BDD patients have appearance-related "obsessions" and "compulsions"), eating disorders (ED; BDD sufferers have a disturbed body image) and social anxiety disorder (SAD; i.e., $\mathrm{BDD}$ sufferers become anxious in social situations because they are concerned that others might notice their perceived appearance defect). ${ }^{14-17}$ Overall, research demonstrated an inverse relationship between social support and treatment outcome in OCD, ${ }^{15,18}$ lower levels of social support among individuals with $\mathrm{ED}$ and SAD compared to healthy controls, ${ }^{14,16,17,19,20}$ and an inverse relationship between social support and disorder severity in SAD. ${ }^{14,19}$

While a relationship between social support and symptom severity was demonstrated for the disorders most similar to BDD, this association was not examined for BDD. Research examining the relationship between social support and $\mathrm{BDD}$ symptom severity is merited, as it could ultimately lead to knowledge of correlates of BDD severity, as well as future research aimed to target this factor in treatment. As such, the present study was designed to examine the association between perceived social support and body dysmorphic symptom severity. Drawing from past literature examining social support, it was hypothesized that lower levels of perceived social support would be associated with more severe BDD symptoms. Consistent with the larger social support literature, which documented a three-factor structure through exploratory factor analyses of adolescent, college, and older adult samples, ${ }^{21-23}$ the present study sought to separately examine the association between perceived social support from each of these three domains, that is, family, friends, and significant others and body dysmorphic symptom severity. Finally, research suggests that gender may moderate the relationship between social support and disorder symptom severity. ${ }^{24-27}$ For example, some studies found that social support was significantly negatively associated with depression among women but not among men. ${ }^{24,27}$ However, opposite findings were also noted. ${ }^{25,26,28}$ For instance, another study demonstrated that social support was more protective against the incidence of depressive and anxiety disorders in men than in women. ${ }^{25}$ Thus, while past literature suggests that gender may moderate the association between social support and disorder severity, it is difficult to draw conclusions across studies. It is therefore important to examine the role of gender in this association in the current study. This study used an internet survey design to examine (1) the association between three domains of perceived social support and body dysmorphic symptom severity, and (2) whether gender moderates these relationships.

\section{Method}

All procedures were approved by the Massachusetts General Hospital institutional review board (protocol number 2008P001825). Data for the present study were collected in conjunction with a larger, internet-based study of participants with symptoms consistent with a diagnosis of $\mathrm{BDD}$.

\section{Participants and procedures}

Participants were recruited via online advertisements posted on BDD-related web pages, in forums, blogs, and support groups, and through the Massachusetts General Hospital OCD and Related Disorders Clinic website. Flyers advertising the study were also posted around the Boston area. Advertisements contained a URL that directed interested participants to the survey website; posted on SurveyMonkey.com. ${ }^{29}$ The survey link was active online between November 2008 and January 2009.

Once logged into the website, participants first encountered an informed consent page, which they were required to read and agree to before continuing. Next, participants were presented with a series of demographic questions, followed by a self-report measure adapted from the BDD-YBOCS and a series of questionnaires about BDD symptoms and psychosocial impairment, including the Multidimensional Scale of Perceived Social Support. ${ }^{22}$ Participants could skip any questions that they did not wish to answer.

At the end of the survey, participants were asked several questions about the relevance and clarity of the survey. Participants received a $\$ 10$ electronic gift certificate as remuneration for participation in the study.

A total of 782 participants initiated the study by agreeing to the information presented on the informed consent page. Participants who reported primary weight concerns were excluded in order to eliminate participants with a likely primary diagnosis of an eating disorder. Additionally, duplicate responses and data from 
responders who did not complete any questions on the primary questionnaire (modified self-report adapted from BDD-YBOCS) were excluded. In order to identify participants with symptoms consistent with a diagnosis of body dysmorphic disorder, the sample was then limited to participants with a 10 -item modified self-report BDD-YBOCS score of 16 or greater, to reflect the YaleBrown Obsessive Compulsive Scale's (Y-BOCS') ${ }^{30}$ cutoff score for clinically significant symptoms. Thus, a final sample of $\mathrm{N}=400$ participants (310 females, 90 males) was included in analyses.

\section{Measures}

1) Demographic questions

Demographic data were collected for participants.

2) Body Dysmorphic Symptom Severity

We adapted the 10-item version of the clinician-administered Yale-Brown Obsessive Compulsive Scale modified for BDD $(B D D-Y B O C S)^{31}$ to create a self-report measure of symptom severity. Modeled after the Y-BOCS,${ }^{30}$ the BDD-YBOCS is a measure of past-week BDD symptom severity. Rather than using the 12-item version, which includes an item on insight that cannot be assessed via self-report, we used the 10 -item version, which excludes this item. The self-report scale was presented in a Likert-type format from 0 (least extreme) to 4 (most extreme), with higher total scores indicating more severe BDD symptomatology. Psychometric properties of the 12-item BDD-YBOCS indicate good internal consistency $(\alpha=0.80)$, convergent validity ( $\mathrm{r}$ $=0.55$ with the Clinical Global Impression Scale), test-retest reliability (intra-class correlation for total score $=0.99$ and 0.88 , respectively), and sensitivity to change with treatment. ${ }^{31}$ The psychometric properties of the clinician-administered 10 -item version are comparable for reliability, factor structure, convergent and discriminant validity, and sensitivity to change. ${ }^{31}$ In the present study, the BDD-YBOCS had good internal consistency $(\alpha=0.76)$ despite its use as a self-report measure.

3) Perceived Social Support

Perceived social support was measured using the Multidimensional Scale of Perceived Social Support (MSPSS). ${ }^{22}$ The MSPSS is a 12-item Likert-type scale containing three subscales: family, friends, and significant other. Items range from one to seven. To calculate total scores for each of the subscales, responses for items in the subscales are averaged, with higher scores indicating greater perceived social support. A total perceived social support score can also be calculated by summing up the three subscales. The MSPSS has strong internal consistency $(\alpha=0.88)$ and good construct validity when correlated with the Hopkins Symptom Checklist (HSCL) Depression and Anxiety subscales. ${ }^{22}$ In the present study, the MSPSS also demonstrated excellent internal consistency for the family subscale $(\alpha=0.93)$, friends subscale $(\alpha=0.93)$, and significant other subscale $(\alpha=0.95)$.

4) Depression and anxiety

The Depression Anxiety Stress Scale-21 Item Version (DASS$21)^{32}$ was used to measure symptoms of depression, anxiety, and stress by way of three self-report subscales. This information was used to control for depression during analyses. In a large, non-clinical sample, the depression, anxiety, and stress subscales demonstrated strong internal consistency ( $\alpha=0.88,0.82$, and 0.90 , respectively). ${ }^{33}$ In a clinical sample, the subscales also demonstrated strong internal consistency $(\alpha=0.96,0.89$, and 0.93 , respectively). ${ }^{34}$ Finally, in the present sample, the three subscales were shown to have strong internal consistency ( $\alpha=0.87,0.83$, and 0.82 , respectively).

\section{Analytical strategy}

Statistical analyses were conducted using SPSS version 17.0. Group differences in BDD symptom severity and depression were tested. The first aim was to examine the association between the three domains of perceived social support and body dysmorphic symptom severity. To this end, the family, friends, and significant other subscales of the MSPSS were correlated with the BDDYBOCS for both males and females.

The second goal of the current study was to test whether gender moderated the association between perceived social support and BDD symptom severity. For these analyses, three multiple regressions were used for the three subscales of the MSPSS. Multiple regression was chosen in part because it does not require the sample to have an equal gender distribution. ${ }^{35,36}$ The predictor variables for the three regressions (MSPSS family, friends, and significant other subscales) were centered for the purpose of interpretation, and three interaction terms were created with the three predictor variables and gender. For each of the three models, the BDD-YBOCS score was then regressed on the predictor variable and the appropriate interaction term. Because depression is commonly comorbid with BDD and has been shown to be associated with social support, it was entered as a covariate in each of the three regressions. The correlation between depression and anxiety was approaching collinearity. Therefore anxiety was not entered as a covariate. In order to probe significant interactions, a simple slope test was used. ${ }^{35}$

\section{Results}

Participants ranged in age from 18 to 62 years, and had a mean (SD) age of 31.57 (9.79) years. The majority of participants were Caucasian $(\mathrm{N}=292 ; 73 \%)$ and half of the participants were employed either full-time of part-time $(\mathrm{N}=230)$. One hundred and fifty-two of the participants were single (38\%), while 220 were either dating, married, or cohabitating (55\%).

Sample means and standard deviations for the BDD-YBOCS, DASS-21 depression subscale, and MSPSS are presented in Table 1. Prior to conducting our primary analysis, we examined if there were group differences in our primary outcome variable (e.g., BDD-YBOCS) since such differences would bias the proposed moderation analysis. Results suggested that there were no group differences in BDD-YBOCS scores for males as compared to females $(t(399)=-1.02, \mathrm{p}=0.31)$, suggesting that males and females in the sample had similarly severe body dysmorphic symptoms. 
Table 1 - Correlations, sample means and standard deviations for outcome measures by gender

\begin{tabular}{|c|c|c|c|c|c|c|c|c|}
\hline \multirow{3}{*}{ Measure } & \multicolumn{4}{|c|}{ Males } & \multicolumn{4}{|c|}{ Females } \\
\hline & $r$ & & & & $\mathbf{r}$ & & & \\
\hline & BDD-YBOCS & $\mathbf{N}$ & Mean & SD & BDD-YBOCS & $\mathbf{N}$ & Mean & SD \\
\hline BDD-YBOCS & - & 90 & 21.66 & 4.17 & - & 310 & 22.18 & 4.28 \\
\hline DASS-21 & $0.41^{* *}$ & 86 & 20.30 & 10.11 & $0.44^{* *}$ & 270 & 21.19 & 11.14 \\
\hline MSPSS Family & -0.17 & 87 & 4.47 & 1.52 & $-0.20^{\star *}$ & 274 & 4.03 & 1.65 \\
\hline MSPSS Friends & $-0.27^{*}$ & 86 & 4.27 & 1.60 & $-0.20^{\star *}$ & 271 & 3.92 & 1.66 \\
\hline MSPSS Significant Other & $-0.32^{* *}$ & 86 & 4.35 & 1.62 & -0.08 & 273 & 4.65 & 1.75 \\
\hline
\end{tabular}

BDD-YBOCS $=10$ item Yale Brown Obsessive Compulsive Scale Modified for BDD; DASS-21 = Depression Anxiety Stress Scale-21 Item; MSPSS = Multidimensional Scale of Perceived Social Support; * Results significant at the 0.05 level (2-tailed); ${ }^{* *}$ Results significant at the 0.01 level (2-tailed)

First-order correlations were run to examine the association between scores on the BDD-YBOCS and the three subscales of the MSPSS for males and females (Table 1). As predicted, there were significant negative associations between perceived social support from friends and significant others and body dysmorphic symptom severity among males. Perceived social support from family and friends was also significantly negatively associated with body dysmorphic symptom severity in females. In other words, the more social support participants had, the less severe their BDD was. Contrary to hypotheses, perceived social support from family was not significantly associated with symptom severity in males, and perceived social support from significant others was not significantly associated with symptom severity in females.

In order to examine the role of gender as a moderator of these relationships, three moderation analyses were conducted, controlling for depression in each regression. The regression analyses demonstrated that gender did not moderate the relationship between perceived social support from family and body dysmorphic symptom severity $(\beta=0.075, \mathrm{t}=1.52$, $\mathrm{p}=0.13)$, nor did it moderate the relationship between perceived social support from friends and symptom severity, $(\beta=.087$, $\mathrm{t}=1.80, \mathrm{p}=0.07)$. However, gender did moderate the relationship between perceived social support from significant others and symptom severity, as shown by a significant overall model, $\mathrm{F}(4,350)=24.06, \mathrm{p}<0.001$, and a significant interaction term between support from significant others and gender, $(\beta=0.13, t=2.75, p=0.01)$. A simple slope test revealed that perceived social support from a significant other was significantly associated with symptom severity for males $(\beta=-0.23, p<0.01)$, but not for females ( $\beta=0.04, p=0.58)$; see Figure 1. For males, perceived social support from significant others accounted for $21.6 \%$ of variance in symptom severity.

\section{Discussion}

The aim of the present study was to examine the association between perceived social support and body dysmorphic symptom severity in an internet sample with symptoms consistent with a diagnosis of BDD. Furthermore, the role of gender as a potential moderator of this relationship was examined.
In males, less perceived social support from friends and significant others was associated with increased body dysmorphic symptom severity. Given that the current study is adequately powered for the proposed analysis, it is unlikely that the nonsignificant association between perceived social support from family and body dysmorphic symptom severity in males is due to lack of power. For females, results revealed that less perceived social support from family and friends was associated with increased body dysmorphic symptom severity, while the association between perceived social support from significant others and symptom severity was non-significant.

Findings that participants with less perceived social support experienced greater body dysmorphic symptom severity are consistent with the broader social support literature. ${ }^{19,25}$ Although correlations were weak in magnitude, they were stronger than those reported in studies of other disorders, such as SAD.${ }^{19}$ Considering the high degree of impairment associated with BDD, results implicate social support as an important area of future BDD research.

Moderation analyses revealed that gender moderated the relationship between social support from significant others and BDD symptom severity so that this relationship was significant only among males, and not females. Gender did not moderate the relationships between social support from family and friends and BDD symptoms.

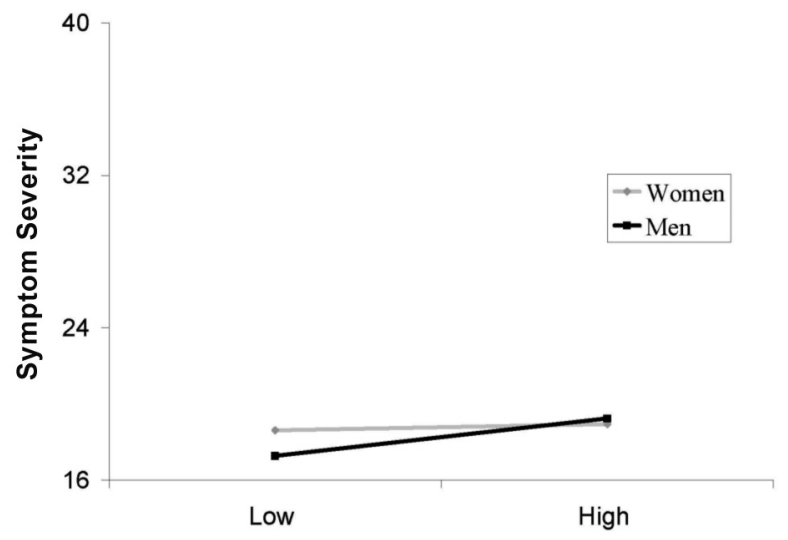

Figure 1 - Social support from significant other 
One way to expand our interpretation of these results is by considering the greater social support literature. The support gap hypothesis postulates that men receive more spousal support than do women, perhaps due to women's socialized gender role as caregivers. ${ }^{37,38}$ Studies have also shown that women benefit less than men from social support provided by a romantic partner. ${ }^{38}$ As such, women in the present sample may receive less social support from romantic partners than men in the present sample, therefore benefiting less from this domain of social support. Given that the length of a romantic relationship might have an impact on social support and body dysmorphic symptoms, future studies should consider including relationship length as a covariate.

The present study has limitations. First, causality cannot be inferred from the correlational analyses. Thus, it is impossible to know if perceived social support influenced the severity of body dysmorphic symptoms, or if individuals with more severe BDD were too impaired to form social relationships in the first place and were, therefore, less likely to receive social support from others around them.

It is also possible that these two phenomena had a bidirectional relationship, in which lower perceived social support led to more severe BDD symptoms, which in turn inhibited the individuals' ability to mobilize social support. Second, although we controlled for the most likely confounding variable, that is, depression, it is possible that other confounding variables, such as other comorbid psychological disorders (e.g., OCD and SAD), might have influenced the results.

Additionally, there are several limitations associated with the use of an internet study design. First, a sampling bias may have resulted from collecting data over the internet given that not all populations have equal computer access or skills. However, research suggests that internet surveys deliver data that are equally reliable to that of other study designs. ${ }^{39,40}$ It is important to highlight that the current study had a larger proportion of females compared to males. Although this might seem unusual given previous studies that have documented that BDD is similarly prevalent in both genders, newer data suggests that BDD appears to affect slightly more females than males. ${ }^{41-43}$ Additionally, these results are consistent with other Internet studies, which seem to draw more female than male participants. ${ }^{44}$ Future studies might consider additional recruiting strategies targeting males that might help address this sampling bias. Furthermore, because data were collected through self-report via the internet, formal diagnosis of BDD by a clinician was not possible. Thus, it is difficult to know whether the present findings apply to patients with clinically-diagnosed BDD. Future internet studies might want to invite a small subset of the sample to a clinical setting to conduct a confirmatory diagnostic assessment. This limitation was minimized by the inclusion of participants with symptom severity comparable to a formal diagnosis of $\mathrm{BDD}$, as indicated by scores on the self-report measure adapted from the BDD-YBOCS. Finally, the self-report version of the 10-item BDD-YBOCS used in the present sample has never been used before, although its internal consistency in the current study was acceptable.
It should also be noted that the use of internet data collection may have increased the external validity of the sample in several important ways. For instance, the sample may have included participants who, due to the shame and stigma associated with having $\mathrm{BDD}$, might not have been willing to come into a clinic to be assessed. It is also possible that using an internet survey to collect data may have promoted a larger geographic representation of the sample as opposed to collecting data from within a clinical setting. Finally, the use of an internet survey design allowed for the collection of data from both treatment seeking and non-treatment seeking individuals.

\section{Conclusion}

Ultimately, in light of the aforementioned limitations, findings from the present study require future examination in participants formally diagnosed with BDD and, if possible, through a longitudinal design. If replicated, future researchers should consider the potential clinical implications of these results. More specifically, future investigations could examine the effectiveness of cognitive behavioral interventions aimed to address low perceived social support by highlighting available support networks and developing or expanding support networks. It could also be helpful to involve family members or significant others in therapy for this reason.

In summary, the present study addressed a gap in our understanding of whether social support is related to BDD symptom severity and whether gender influences this relationship. Findings suggest that the specific domain of perceived social support may be an important area of future research for BDD. 
Disclosures

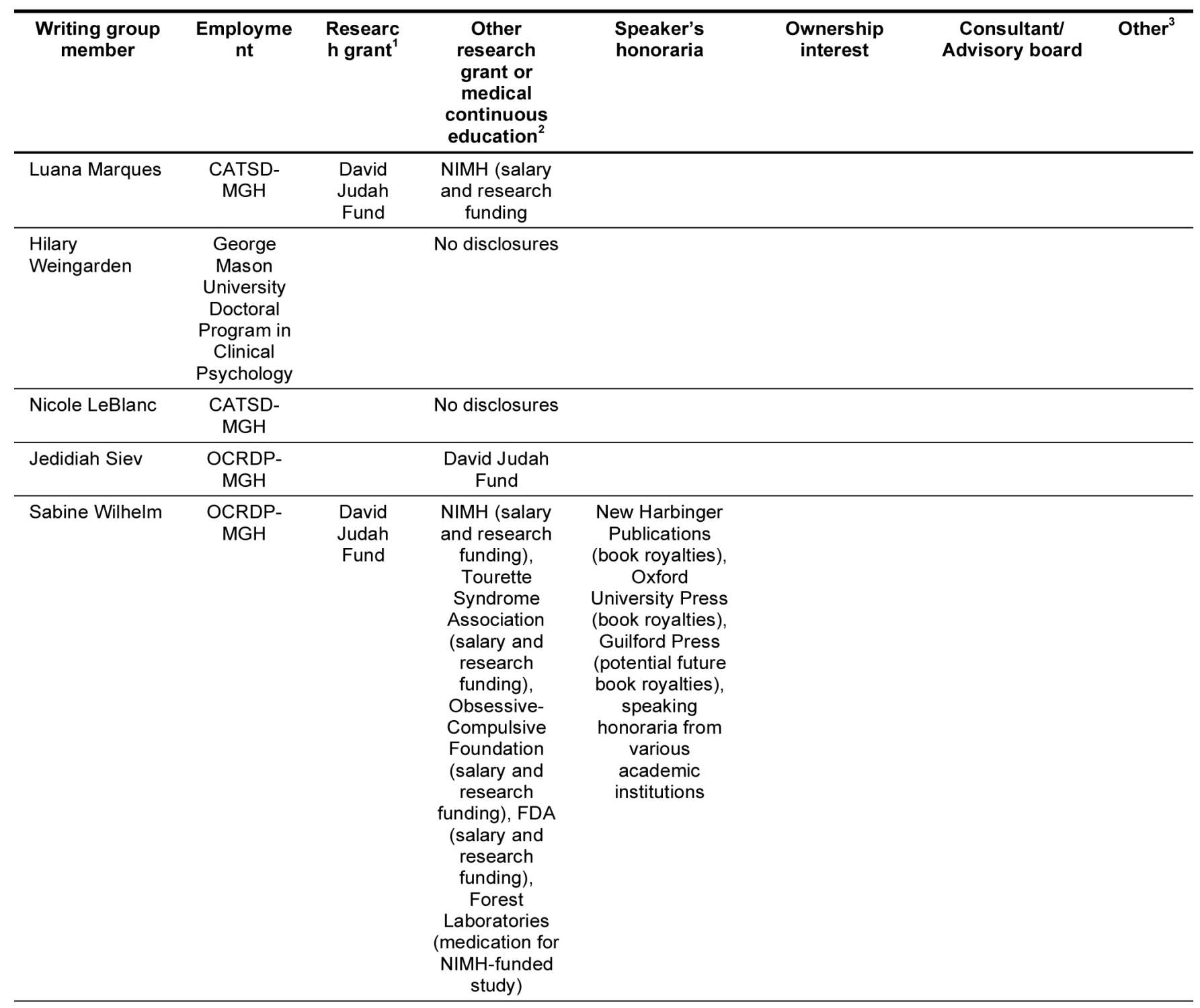

* Modest

** Significant

***Significant: Amounts given to the author's institution or to a colleague for research in which the author has participation, not directly to the author.

CATSD: Center for Anxiety and Traumatic Stress Disorders; MGH: Massachusetts General Hospital; OCRDP: ObsessiveCompulsive and Related Disorders Program; NIMH: National Institute of Mental Health; FDA: Food and Drug Administration

\section{References}

1. American Psychiatry Association. Diagnostic and statistical manual of mental disorders. 4th ed., text-revision ed. Washington, DC: American Psychiatric Association; 2000.

2. Rief W, Buhlmann U, Wilhelm S, Borkenhagen A, Brähler E. The prevalence of body dysmorphic disorder: A population-based survey. Psychol Med. 2006;36(6):877-85.

3. Phillips KA, Didie ER, Menard W, Pagano ME, Fay C, Weisberg RB. Clinical features of body dysmorphic disorder in adolescents and adults. Psychiatry Res. 2006;141(3):305-14.

4. Phillips KA, Didie ER, Feusner J, Wilhelm S. Body dysmorphic disorder: treating an underrecognized disorder. Am J Psychiatry. 2008;165(9):1111-8.

5. Bienvenu OJ, Samuels JF, Riddle MA, Hoehn-Saric R, Liang KY, Cullen BA, Grados MA, Nestadt G. The relationship of obsessive-compulsive disorder to possible spectrum disorders: Results from a family study. Bio Psychiatry. 2000;48(4):287-93.
6. Phillips KA, Quinn G, Stout RL. Functional impairment in body dysmorphic disorder: a prospective, follow-up study. J Psychiatr Res. 2008;42(9):701-7.

7. Conroy M, Menard W, Fleming-Ives K, Modha P, Cerullo H, Phillips KA. Prevalence and clinical characteristics of body dysmorphic disorder in an adult inpatient setting. Gen Hosp Psychiatry. 2008;30(1):67-72.

8. Grant JE, Kim SW, Crow SJ. Prevalence and clinical features of body dysmorphic disorder in adolescent and adult psychiatric inpatients. JClin Psychiatry. 2001;62(7):517-22. 9. Phillips KA, Menard W, Fay C, Weisberg R. Demographic characteristics, phenomenology, comorbidity, and family history in 200 individuals with body dysmorphic disorder. Psychosomatics. 2005;46(4):317-25.

10. Fontenelle LF, Telles LL, Nazar BP, de Menezes GB, do Nascimento AL, Mendlowicz MV, Versiani M. A sociodemographic, phenomenological, and longterm follow-up study of patients with body dysmorphic disorder in Brazil. Int J Psychiatry Med. 2006;36(2):243-59. 
11. Phillips KA, Menard W, Fay C, Pagano ME. Psychosocial functioning and quality of life in body dysmorphic disorder. Compr Psychiatry. 2005;46(4): 254-60.

12. Phillips KA. Quality of life for patients with body dysmorphic disorder. J Nerv Ment Dis. 2000;188(3):170-5.

13. Phillips KA. The broken mirror: understanding and treating body dysmorphic disorder. New York, NY US: Oxford University Press; 1996.

14. Davidson JR, Hughes DC, George LK, Blazer DG. The boundary of social phobia: Exploring the threshold. Arch Gen Psychiatry. 1994;51(12): 975-83.

15. Steketee G. Social support and treatment outcome of obsessive compulsive disorder at 9-month follow-up. Behav Psychother. 1993;21(2):81-95.

16. Stice $\mathrm{E}$, Whitenton K. Risk factors for body dissatisfaction in adolescent girls: a longitudinal investigation. Develop Psychol. 2002;38(5):669-78.

17. Tiller JM, Sloane G, Schmidt U, Troop N. Social support in patients with anorexia nervosa and bulimia nervosa. Int J Eating Disord. 1997; 21(1):31-8.

18. Steketee G, Eisen J, Dyck I, Warshaw M, Rasmussen S. Predictors of course in obsessive-compulsive disorder. Psychiatry Res. 1999;89(3):229-38.

19. Torgrud LJ, Walker JR, Murray L, Cox BJ, Chartier M, Kjernisted KD. Deficits in perceived social support associated with generalized social phobia. Cogn Behav Ther. 2004;33(2):87-96.

20. Gerner B, Wilson PH. The relationship between friendship factors and adolescent girls' body image concern, body dissatisfaction, and restrained eating. Int J Eating Disord. 2005;37(4):313-20.

21. Kazarian SS, McCabe SB. Dimensions of social support in the MSPSS: factorial structure, reliability, and theoretical implications. J Community Psychol. 1991;19(2):150-60.

22. Zimet GD, Dahlem NW, Zimet SG, Farley GK. The multidimensional scale of perceived social support. J Personality Assess. 1988;52(1):30-41.

23. Stanley MA, Beck JG, Zebb BJ. Psychometric properties of the MSPSS in older adults. Aging Ment Health. 1998;2(3):186-93.

24. Kendler KS, Myers J, Prescott CA. Sex differences in the relationship between social support and risk for major depression: a longitudinal study of opposite-sex twin pairs. Am J Psychiatry. 2005;162(2):250-6.

25. Plaisier I, de Bruijn JG, de Graaf R, ten Have M, Beekman AT, Penninx BW. The contribution of working conditions and social support to the onset of depressive and anxiety disorders among male and female employees. Soc Sci Med. 2007;64(2):401-10

26. Shumaker SA, Hill DR. Gender differences in social support and physical health. Health Psychol. 1991;10(2):102-11.

27. Wareham S, Fowler K, Pike A. Determinants of depression severity and duration in Canadian adults: the moderating effects of gender and social support. J Applied Soc Psychol. 2007;37(12):2951-79.

28. Berkman LF, Cohen S, Syme SL. The relationship of social networks and social support to morbidity and mortality. Social support and health. San Diego, CA US: Academic Press; 1985. p.241-62.

29. Finley R. SurveyMonkey.com. 1999 [cited 2008 dez 30]; Available from: www.surveymonkey.com

30. Goodman WK, Price LH, Rasmussen SA, Mazure C. The Yale-Brown Obsessive Compulsive Scale: I. Development, use, and reliability. Arch Gen Psychiatry. 1989;46(11):1006-11.

31. Phillips KA, Hollander E, Rasmussen SA, Aronowitz BR. A severity rating scale for body dysmorphic disorder: Development, reliability, and validity of a modified version of the Yale-Brown Obsessive Compulsive Scale. Psychopharmacol Bull. 1997;33(1):17-22.

32. Lovibond PF, Lovibond SH. The structure of negative emotional states: comparison of the Depression Anxiety Stress Scales (DASS) with the Beck Depression and Anxiety Inventories. Behav Res Ther. 1995;33(3):335-43.

33. Henry JD, Crawford JR. The short-form version of the Depression Anxiety Stress Scales (DASS-21): Construct validity and normative data in a large nonclinical sample. Br J Clin Psychol. 2005;44(2):227-39.

34. Brown TA, Chorpita BF, Korotitsch W, Barlow DH. Psychometric properties of the Depression Anxiety Stress Scales (DASS) in clinical samples. Behav Res Ther. 1997;35(1):79-89.
35. Aiken LS, West SG. Multiple regression: testing and interpreting interactions. Thousand Oaks, CA US: Sage Publications, Inc; 1991.

36. Cohen J. A power primer. Psychol Bull. 1992;112(1):155-9.

37. Belle D. The stress of caring: Women as providers of social support. In: Breznitz LGS, editor. Handbook of stress: theoretical and clinical aspects. New York: Free Press; 1982. p.496-505.

38. Schwarzer R, Gutierrez-Dona B. More spousal support for men than for women: a comparison of sources and types of support. Sex Roles. 2005;52(7):523-32.

39. Coles ME, Cook LM, Blake TR. Assessing obsessive compulsive symptoms and cognitions on the internet: Evidence for the comparability of paper and Internet administration. Behav Res Ther. 2007;45(9):2232-40.

40. Kongsved SM, Basnov M, Holm-Christensen K, Hjollund NH. Response rate and completeness of questionnaires: a randomized study of Internet versus paper-and-pencil versions. J Med Internet Res. 2007;9(3):39-48.

41. Phillips KA, Diaz SF. Gender differences in body dysmorphic disorder. J Nerv Ment Dis. 1997;185(9):570-7.

42. Phillips KA, Menard W, Fay C. Gender similarities and differences in 200 individuals with body dysmorphic disorder. Compr Psychiatry. 2006;47(2):77-87. 43. Perugi G, Akiskal HS, Giannotti D, Frare F, Di Vaio S, Cassano GB. Genderrelated differences in body dysmorphic disorder (dysmorphophobia). J Nerv Ment Dis. 1997;185(9):578-82.

44. Woods DW, Flessner CA, Franklin ME, Keuthen NJ, Goodwin RD, Stein DJ, Walther MR; Trichotillomania Learning Center-Scientific Advisory Board. The trichotillomania impact project (TIP): Exploring phenomenology, functional impairment, and treatment utilization. J Clin Psychiatry. 2006;67(12):1877-88. 